\title{
Head Injury in Soccer: From Science to the Field; summary of the head injury summit held in April 2017 in New York City, New York
}

\author{
Margot Putukian (ㄱ, , Ruben J Echemendia, ${ }^{2}$ George Chiampas, ${ }^{3}$ Jiri Dvorak, ${ }^{4,5}$ \\ Bert Mandelbaum, ${ }^{6}$ Lawrence J Lemak, ${ }^{7}$ Don Kirkendall ${ }^{8}$
}

\begin{abstract}
- Additional material is published online only. To view, please visit the journal online (http://dx.doi.org/10.1136/ bjsports-2018-100232).
\end{abstract}

'Department of Athletic Medicine, Princeton University, Princeton, New Jersey, USA ${ }^{2}$ Department of Concussion Clinic, University Orthopaedics Center, State College,

Pennsylvania, USA

${ }^{3}$ Department of Emergency

Medicine \& Orthopedics,

Feinberg School of Medicine, Northwestern University, Chicago, Illinois, USA ${ }^{4}$ Swiss Concussion Center, Zurich, Switzerland ${ }^{5}$ Department of Spine Unit, Schulthess Clinic, Zurich, Switzerland

${ }^{6}$ Santa Monica Orthopaedic and Sports Med Group, Santa Monica, UK

${ }^{7}$ Lemak Health, Birmingham, Alabama, USA

${ }^{8}$ Duke Sport Sciences Institute, Duke University Health System, Durham, North Carolina, USA

\section{Correspondence to}

Dr Margot Putukian, Athletic Medicine, Princeton University University Health Services, Princeton, NJ 08544, USA putukian@princeton.edu

Accepted 22 January 2019

Published Online First

13 February 2019

Check for updates

(C) Author(s) (or their employer(s)) 2019. No commercial re-use. See rights and permissions. Published by BMJ.

To cite: Putukian $\mathrm{M}$ Echemendia RJ, Chiampas G, et al. Br J Sports Med 2019:53:1332.

\section{ABSTRACT}

There has been an increased focus and awareness of head injury and sport-related concussion (SRC) across all sports from the medical and scientific communities, sports organisations, legislators, the media and the general population. Soccer, in particular, has been a focus of attention due to the popularity of the game, the frequency of SRC and the hypothesised effects of repetitive heading of the ball. Major League Soccer, US Soccer and the National Women's Soccer League jointly hosted a conference entitled, 'Head Injury in Soccer: From Science to the Field', on 21-22 April 2017 in New York City, New York. The mission of this conference was to identify, discuss and disseminate evidence-based science related to the findings and conclusions of the fifth International Conference on Concussion in Sport held by the Concussion in Sport Group and apply them to the sport of soccer. In addition, we reviewed information regarding the epidemiology and mechanism of head injuries in soccer at all levels of play, data regarding the biomechanics and effects of repetitive head impacts and other soccer-specific considerations. We discussed how to release the information raised during the summit to key stakeholders including athletes, parents, coaches and healthcare providers. We identified future areas for research and collaboration to enhance the health and safety of soccer (football) players.

\section{INTRODUCTION}

Sport-related concussion (SRC) is a frequent injury in many sports, and the most recent international conference on Concussion in Sport Group (CISG) published its findings in 2017. ${ }^{1}$ Soccer, in particular, has been a focus of attention due to the popularity of the game, the frequency of SRC and the hypothesised effects of repetitive heading of the ball. Major League Soccer (MLS), US Soccer and the National Women's Soccer League (NWSL) jointly hosted a head injury summit (HIS) entitled, 'Head Injury in Soccer: From Science to the Field', on 21-22 April 2017 in New York City, New York. The mission of this historic collective multiorganisational group was to build on the CISG's most recent international conference ${ }^{1}$ by identifying, discussing and disseminating evidence-based science related to principles, policies and programmes in soccer across genders, the age spectrum and levels of training and competitive play. Key components of this meeting included in-depth examination of education, research, practice and play in the sport of soccer with the goal of enhancing the health and safety of players in the present and in the future.

This paper summarises the presentations, discussions and conclusions of the soccer summit. This document will review issues raised during the HIS (see online supplementary appendix A: Final Programme) using information provided by each speaker compiled and reviewed by the programme committee (Putukian, Echemendia, Chiampas, Mandelbaum, Dvořák, Lemak) and the speakers. The summary that follows represents the current state of knowledge regarding SRC in soccer, with the understanding that this is a rapidly evolving field with new research and information constantly emerging.

\section{WHAT WE KNOW AND KNOWLEDGE GAPS}

To apply lessons learnt from the 2016 fifth International Consensus Statement on Concussion in Sport to the sport of soccer, it is important to determine what is known, what knowledge gaps exist and what interventions can be implemented to improve the health and safety of its players. We will address the epidemiology of concussions including mechanisms of injury, the role of purposeful heading and the aerial challenge and review data from the USA and abroad at all levels of play. Although there is valuable information available, there remains a paucity of data for youth players, and more research is necessary at this level of play.

When evaluating studies of injury epidemiology, it is important to understand that the definition of injury (eg, whether a time loss injury or one that requires medical attention) may be different, the methodology of data collection (eg, self-report, online vs written survey, game report vs video or observer report), as well as other variables (eg, incidence data as athlete exposures (AE) vs exposure hours), definition of concussion and the details regarding the mechanism of injury, should all be considered.

The acute assessment of head injury and concussion in soccer is similar to other sports, with emphasis on an Emergency Action Plan, early recognition (eg, Concussion Recognition Tool (CRT)) ${ }^{2}$ and the utility of a standardised multimodal assessment such as the Sport Concussion Assessment Tool $(\mathrm{SCAT})^{3}$ and the Child SCAT. ${ }^{4}$ The protocols for management of SRC and return to both academics and sport participation are also similar for the soccer player, but a significant knowledge gap remains in terms of understanding the difference between clinical recovery and physiological recovery. Although 
several specific biomarkers of head injury and concussion exist, including blood, genetic and neuroimaging techniques, these currently remain investigational. More information is needed before implementation in clinical management. We will review the challenges of early recognition, assessment of injury and the role of sensors and of spotter technology in injury detection for soccer, as well as other unique obstacles to assessment and management of SRC in soccer.

Heading is a sport-specific skill that is unique to soccer, where the head is used to purposefully strike the ball to redirect it. There have been questions raised regarding whether there are acute or chronic effects of heading. While successful purposeful heading is an infrequent cause of concussion, the aerial challenge, where players challenge for a ball in the air, is a common player behaviour that has been mislabelled as a mechanism of head injury. More accurately and specifically, head-to-head, elbow-to-head, knee-to-head, foot-to-head and head-to-ground are the most common mechanisms of injury. This complicates some of the interpretation of epidemiology studies evaluating injury in soccer. Although the biomechanics of heading and the aerial challenge have been evaluated in the laboratory setting, more information is needed about what occurs on the field as well as what the chronic effects, if any, of soccer play may be.

There are questions related to potential acute and chronic effects of heading alone, unrelated to concussion, which represents the presence of another knowledge gap. We will present the prospective data, although limited, which do not demonstrate significant immediate or short-term (over the course of a season) effects of heading. There are case reports of soccer players with chronic traumatic encephalopathy (CTE), but no evidence that soccer play causes CTE. More research is needed to evaluate whether a relationship exists and the nature of that relationship.

Prevention of concussion and head injury in soccer includes efforts that are not unique to the sport, such as education, improved recognition and the use of standardised assessment, as well as soccer-specific approaches such as considering rule changes, enforcement of existing rules, using the proper sized ball with correct inflation, considering other ball or surface properties and neck strengthening. Restricting heading, in an attempt to limit the aerial challenge and thus decrease head injuries, is another prevention effort that represents an area of further discussion and research. Our stakeholders, including athletes, coaches, referees, administrators, along with the healthcare team play a significant role in supporting and enhancing the health and safety of our sport and players.

\section{EPIDEMIOLOGY AND MECHANISMS OF HEAD INJURY IN SOCCER}

High school and youth

According to FIFA, there are 265 million registered soccer players worldwide, including 26 million women, and 22 million registered youth soccer participants, ${ }^{5}$ with 4.2 million coming from the USA ( 2.5 million male, 1.7 million female). Between 2000 and 2006, there was a 54\% and 21\% increase worldwide in the number of female and male participants registered, respectively. ${ }^{5}$ Of the youth players in the USA, 19721 players participate in Developmental Academies (DA), ${ }^{6}$ which includes several age groups ranging from under (U)-12 to U-18-19 years, for both male and female players, participating in elite player development as part of US Soccer. In the 2017-2018 season, the DA programmes included 896 teams in 197 clubs, with over 13000 games. $^{6}$
Faude et al summarised the literature regarding injuries to children and adolescent soccer players (aged 5-19 years) and reported that about $5 \%$ of all injuries in these age groups were to the head. ${ }^{7}$ The percentage of concussions ranged between $1 \%$ and $7 \%$ across studies with the majority reporting $2 \%$ or fewer. Faude et al followed up their review with a prospective project of children aged 7-12 years focusing their attention on 39 head injuries (5\% of all 791 injuries), of which 11 (28\% of all head and neck injuries) were classified as concussion. ${ }^{8}$ Seventy-five per cent of injuries were due to contact with another player while ball contact was cited as the injury mechanism for two concussions. In addition, the authors noted that the rate of concussions (per 1000 hours of soccer exposure) increased slightly with age (U-9 $=0.04 ; \mathrm{U}-11=0.07 ; \mathrm{U}-13=0.06$ ).

In a more recent online survey of 8104 youth soccer teams including 101699 players (59621 boys; 42048 girls) aged 7-14 years, (Kontos, 2017, personal communication), the overall reported concussion incidence rate was $0.85 / 1000 \mathrm{AE}$. In this study, concussions were 5.7 times more likely to occur in games $(1.73 / 1000 \mathrm{AEs})$ than practices $(0.27 / 1000 \mathrm{AEs})$. Although there were no significant differences in concussions between boys and girls, older (aged 11-14 years) players (1.08/1000 AEs) were 2.7 times more likely to have concussions than younger (aged 7-10 years) players (0.40/1000 AEs). Only one in five concussions were from attempted soccer heading and no concussions from heading were reported in players younger than 12 years of age that may reflect adherence to recent US Soccer mandated restrictions on heading in young players. Representative data for youth through high school-aged soccer players are presented in table 1 .

The overall rate of SRC in high school soccer in the USA from $2005 / 2006$ to $2013 / 2014$ was estimated to be $0.36 / 1000$ AEs (girls $=0.45 / 1000 \mathrm{AEs}$; boys $=0.28 / 1000 \mathrm{AEs})$ with a higher rate in games than in practices in girls (rate ratio $=15.1)$ compared with boys (rate ratio $=11.0) .{ }^{9}$ The overall rates for high school girls soccer trail American football (0.64/1000 AEs), boys ice hockey $(0.54 / 1000 \mathrm{AEs})$ and boys lacrosse $(0.40 / 1000 \mathrm{AEs}) .^{10}$ During the 2014-2015 academic year, concussions represented the highest proportion of all injuries in girls high school sports. ${ }^{11}$

Among youth and high school players, concussion is the second most common match injury representing approximately $24 \%$ of all injuries. ${ }^{12}$ While concussion rates increased each year, there was a slight increase beginning in $2006,{ }^{13}$ which continued to rise yearly ${ }^{14}$ until plateauing in 2011/2012. ${ }^{9}$ These trends likely reflect greater awareness, better recognition and increased reporting of concussion.

In a retrospective study of high school and youth soccer players, nearly $60 \%$ of concussions involved contact or collision with another player. ${ }^{9}$ The player behaviour of 'heading the ball' represented $28 \%$ of all concussions in high school soccer, $70 \%$ of which were from player-to-player contact, not ball-to-player contact. ${ }^{9}$ Of the concussions that reflected ball-to-head mechanisms, it is unclear just how many involved successful purposeful heading of the ball; contact may have been purposeful or accidental. Previous prospective reports in collegiate players found that no concussions were due to intentional, purposeful heading. ${ }^{15}$ Recently, researchers reported that $75 \%$ of concussions in youth and high school soccer players occurred when the player was unaware of the oncoming contact or collision. ${ }^{16}$ Concussions from unexpected collisions and contact led to longer symptom duration than when a player was aware of (and presumably braced for) the oncoming contact or collision. These findings suggest situational awareness may influence concussion risk and clinical outcomes following injury. 
Table 1 Summary of concussion rates (per 1000 athlete exposure) in youth and adolescent (aged 7-18 years) soccer players by sex and setting

\begin{tabular}{|c|c|c|c|c|c|c|c|}
\hline \multirow[b]{2}{*}{ Study } & \multirow[b]{2}{*}{ Study years } & \multicolumn{3}{|l|}{ Male } & \multicolumn{3}{|l|}{ Female } \\
\hline & & Training & Match & Overall & Training & Match & Overall \\
\hline $\begin{array}{l}\text { Powell } \\
\text { and Barber- } \\
\text { Foss }^{138}\end{array}$ & 1995-1997 & 0.04 (0.01 to 0.06 ) & 0.57 (0.43 to 0.72 ) & 0.18 (.014 to 0.22$)$ & 0.05 (0.02 to 0.08$)$ & 0.71 (0.53 to 0.88$)$ & 0.23 (0.18 to 0.28 ) \\
\hline Schulz et al $\left.\right|^{139}$ & 1996-1999 & 0.27 (0.00 to 0.64 ) & 5.93 (1.81 to 10.06$)$ & 2.33 (0.84 to 3.82 ) & 0.79 (0.00 to 1.98$)$ & 1.99 (0.43 to 3.94$)$ & 1.32 (0.00 to 2.73 ) \\
\hline Lincoln et $a 1^{13}$ & $1997-2008$ & & & $0.17(0.14$ to 0.20$)$ & & & 0.35 (0.30 to 0.40$)$ \\
\hline Rosenthal et al ${ }^{14}$ & $2005-2006$ & & & 0.22 (0.16 to 0.31$)$ & & & 0.36 (0.27 to 0.47$)$ \\
\hline Gessel et al ${ }^{140}$ & $2005-2006$ & 0.04 & 0.59 & 0.22 (0.14 to 0.30$)$ & 0.09 & 0.97 & 0.36 (0.26 to 0.46$)$ \\
\hline Schallmo et a $\left.\right|^{11}$ & 2005-2006 & & & 0.23 & & & 0.36 \\
\hline Marar et $a l^{10}$ & $2008-2010$ & $0.4(0.20$ to 0.60$)$ & $5.3(4.19$ to 6.41$)$ & 1.9 (1.53 to 2.27$)$ & 0.8 (0.49 to 1.11$)$ & 9.2 (7.64 to 10.76$)$ & 3.4 (2.87 to 3.93$)$ \\
\hline Rosenthall et al ${ }^{14}$ & $2011-2012$ & & & 0.41 (0.32 to 0.52 ) & & & 0.73 (0.60 to 0.89 ) \\
\hline Comstock et al $l^{9}$ & 2005-2014 & & & $0.28(0.25$ to 0.31$)$ & & & 0.45 (0.41 to 0.49$)$ \\
\hline $0^{\prime}$ Connor et al ${ }^{141}$ & $2011-2014$ & 1.48 (0.87 to 2.08 ) & 11.33 (8.46 to 14.20$)$ & 3.98 (3.12 to 4.83 ) & 2.96 (2.04 to 3.88$)$ & 17.16 (13.02 to 21.30$)$ & 6.11 (4.95 to 7.25 ) \\
\hline Schallmo et al ${ }^{11}$ & 2014-2015 & & & 0.30 & & & 0.91 \\
\hline
\end{tabular}

Absence of Cls indicates that either Cls were not reported or that the data necessary to determine Cls were not reported.

In spite of improvements in concussion awareness and recognition, as many as $44 \%$ of youth soccer players indicated that they would not report their concussion symptoms. ${ }^{17}$ This is particularly concerning as researchers recently reported that youth sport participants aged $12-18$ years who continued to play after a concussion were nearly nine times more likely to have a prolonged (>21 days) recovery. ${ }^{18}$ Taubman et al ${ }^{19}$ reported similar findings, with a greater likelihood of prolonged recovery (>30 days) in youth aged 11-19 years who did not rest immediately after concussion versus those who did rest $(67 \%$ vs $35 \%)$. On a positive note, in a recent independent survey, $92 \%$ of players were reported to have sought clinical care for their concussion (Kontos, 2017, personal communication).

\section{Collegiate}

One of the earliest surveillance studies on concussions in college age, male and female players reported the concussion rate to be $0.6 / 1000 \mathrm{AE}$ for men and 0.4/1000 $\mathrm{AE}$ for women. The two most common mechanisms of injury, accounting for half of all concussions, were head-to-head and accidental ball-tohead impacts. No concussions were due to routine, purposeful, successful heading of the ball. ${ }^{15}$ Rates of concussion have risen as injury definitions, injury recognition and reporting have evolved.
The National Collegiate Athletics Association (NCAA) has been the primary source of injury data for collegiate level players since $1986 .{ }^{20}$ Their data indicate that concussion rates are higher in competition when compared with practice in both women's (rate ratio: 8.4-9) and men's soccer (rate ratio: 5.5). ${ }^{2122}$ In comparison with other sports, the NCAA data show the competition concussion rate for men's soccer is less than wrestling, American football and ice hockey while women's soccer trails only ice hockey. ${ }^{22}$ When comparing the match injury rates for women and men, women had a higher rate for both head and face injuries (3.06/1000 AE vs 2.19/1000 AE) as well as concussion $(1.83 / 1000 \mathrm{AE}$ vs $0.94 / 1000 \mathrm{AE}) .^{21}$ Representative data for collegiate soccer players are presented in table 2 .

Injury mechanisms are also available from the NCAA Injury Surveillance Programme. Summaries of 11 years of data for both males and females depict that the majority of concussions do not occur during successful, purposeful heading. In those cases where concussions are associated with heading, the vast majority are due to player-to-player contact rather than player contact with the ball. ${ }^{21} 22$ The proportion of heading-related concussions due to contact with the ball is larger in women's soccer than in men's soccer $(27.4 \%$ vs $10.9 \%$; Parsons, 2017 , personal

Table 2 Summary of concussion rates (per 1000 athlete exposure) in collegiate soccer players by sex and setting

\begin{tabular}{|c|c|c|c|c|c|c|c|}
\hline \multirow[b]{2}{*}{ Study } & \multirow[b]{2}{*}{ Study years } & \multicolumn{3}{|l|}{ Male } & \multicolumn{3}{|l|}{ Female } \\
\hline & & Training & Match & Overall & Training & Match & Overall \\
\hline Boden et $a l^{15}$ & 1995,1996 & & & $0.58(0.26$ to 0.90$)$ & & & 0.40 (0.20 to 0.60$)$ \\
\hline \multirow[t]{3}{*}{ Covassin et $\mathrm{al}^{142 *}$} & 1997-1998 & 0.08 (0.01 to 0.15$)$ & 1.10 (0.89 to 1.81$)$ & & 0.14 (0.09 to 0.16$)$ & 2.04 (2.29 to 1.9$)$ & \\
\hline & 1998-1999 & 0.11 (0.01 to 0.15$)$ & 1.41 (0.89 to 1.81$)$ & & 0.11 (0.09 to 0.16$)$ & 2.04 (2.29 to 1.9$)$ & \\
\hline & 1999-2000 & 0.04 (0.01 to 0.15$)$ & 1.56 (0.89 to 1.81$)$ & & 0.13 (0.09 to 0.16$)$ & 2.21 (2.29 to 1.9) & \\
\hline$\underset{143}{\text { Agel et al (M) }}$ & 1988/1989-2002/2003 & 0.08 (0.06 to 0.09$)$ & 1.08 (0.98 to 1.19$)$ & & & & \\
\hline $\begin{array}{l}\text { Dick et al (F) } \\
144\end{array}$ & 1988/1989-2002/2003 & & & & 0.12 (0.10 to 0.14$)$ & 1.42 (1.29 to 1.55$)$ & \\
\hline Chandran et al ${ }^{145}$ & 2004-2009 & $0.30(0.25$ to 0.35$)$ & 2.19 (1.92 to 2.46$)$ & 0.71 (0.64 to 0.78$)$ & 0.35 (0.29 to 0.41$)$ & 2.49 (2.23 to 2.75$)$ & 0.87 (0.79 to 0.95$)$ \\
\hline Fuller et a $\left.\right|^{146}$ & 2005-2006 (grass) & 0.11 & 1.37 & & 0.13 & 2.17 & \\
\hline Fuller et al $\left.\right|^{147}$ & 2005-2006 (turf) & 0.07 & 2.36 & & 0.21 & 2.00 & \\
\hline Zuckerman et al ${ }^{22}$ & 2009/2010-2013/2014 & 0.18 (0.1 to 0.25$)$ & 0.97 (0.64 to 1.30$)$ & 0.34 (0.25 to 0.44$)$ & 0.21 (0.14 to 0.28$)$ & 1.94 (1.56 to 2.32$)$ & 0.63 (0.52 to 0.74$)$ \\
\hline Kerr et al ${ }^{148}$ & 2009/2010-2013/2014 & 0.14 (0.06 to 0.21$)$ & 0.67 (0.36 to 0.98$)$ & $0.26(0.17$ to 0.65$)$ & $0.18(0.11$ to 0.25$)$ & 1.65 (1.27 to 2.03$)$ & 0.54 (0.43 to 0.064$)$ \\
\hline Roos et $a l^{21}$ & 2009/2010-2014/2015 & $0.17(0.11$ to 0.24$)$ & $0.94(0.65$ to 1.24$)$ & & $0.20(0.14$ to 0.26$)$ & 1.83 (1.5 to 2.16$)$ & \\
\hline
\end{tabular}

Absence of Cls indicates that either Cls were not reported or that the data necessary to determine Cls were not reported.

${ }^{*} \mathrm{Cl}$ were presented as the aggregate of the 3 years of the study. 
communication). Unfortunately, the NCAA data do not identify accidental ball-to-head impacts.

\section{Professional}

Data that are based on professional players come from two similar, but unique settings. The first is the domestic professional season (eg, the English Premier League, La Liga, MLS, etc). The second setting is a tournament (FIFA World Cup (U-17 through full national teams; male and female), Olympics, UEFA Champions League, EURO, etc). While both settings are highly competitive, tournaments are generally assumed to represent the highest and most intense level of competition for the respective age and gender. Data from domestic leagues and tournaments will be presented separately.
Domestic leagues

Concussions are the fifth most common injury in MLS, although injury rates vary by team and by season (table 3$).^{23}$ Similarly, marked variability exists among players in the number of days missed due to concussion. Preliminary data (2014-2016 seasons) reveal that most concussions occurred through contact with an opponent $(71 \%)$, although contact with a teammate $(16 \%)$ was also found. Concussions tended to occur more frequently to defenders (33\%) followed by midfielders (30\%), forwards (24\%) and to a lesser extent the goalkeeper (13\%). Concussive injuries were most common during the last $30 \mathrm{~min}$ of a match $(45 \%)$ and the first $30 \mathrm{~min}(30 \%)$ of a match. Concussions occurred most frequently in the midfield, primarily due to collisions (41\%) and aerial challenges (42\%). The body part most frequently causing

Table 3 Summary of concussion rates (per 1000 player-hours) in professional soccer players by sex, setting and level of play

\begin{tabular}{|c|c|c|c|c|c|c|c|}
\hline \multirow[b]{2}{*}{ Study } & \multirow[b]{2}{*}{ Study years } & \multicolumn{3}{|l|}{ Male } & \multicolumn{3}{|l|}{ Female } \\
\hline & & Training & Match & Overall & Training & Match & Overall \\
\hline \multicolumn{8}{|l|}{ Domestic leagues } \\
\hline $\begin{array}{l}\text { Jacobson and } \\
\text { Tegner }^{35}\end{array}$ & 2000 & & & & & & 0.10 (0.03 to 0.17$)$ \\
\hline Waldén et al ${ }^{44149}$ & 2001 & & & 0.05 (0.01 to 0.09$)$ & & & \\
\hline Gaulrapp et $a l^{\beta 3}$ & n.s. & & & & & & $0.17(0.08$ to 0.26$)$ \\
\hline Hassabi et $a l^{37}$ & $2005-2006$ & & & $0.80(0.00$ to 1.91$)$ & & & \\
\hline Ekstrand et $a l^{\beta 2}$ & $2001-2008$ & & & $0.06(0.04$ to 0.08$)$ & & & \\
\hline \multirow[t]{2}{*}{ Ekstrand et $a l^{\beta 1}$} & 2003-2008 (grass) & 0.07 (0 to 0.05$)$ & $0.74(0.28$ to 1.20$)$ & & $0.15(0.00$ to 0.44$)$ & $0.99(0.00$ to 2.11$)$ & \\
\hline & 2003-2008 (turf) & 0.02 (0 to 0.04$)$ & 0.52 (0.18 to 0.86$)$ & & $0.09(0.00$ to 0.19$)$ & $0.89(0.02$ to 1.76$)$ & \\
\hline Eirale et $a \beta^{38}$ & 2008-2009 & & & $0.03(0.001$ to 0.2$)$ & & & \\
\hline \multirow[t]{2}{*}{ Waldén et $a l^{150}$} & 2009-2010* & & & $0.07(0.05$ to 0.09$)$ & & & \\
\hline & 2009-2010† & & & 0.03 (0.01 to 0.07$)$ & & & \\
\hline Nilsson et $a l^{36}$ & $2001-2010$ & $0.01(0.00$ to 0.01$) \ddagger$ & 0.35 (0.26 to 0.47$)$ & $0.06(0.04$ to 0.08$)$ & & & \\
\hline \multirow[t]{3}{*}{ Beaudouin et al ${ }^{130}$} & 2000-2006 & & $0.67(0.51$ to 0.88$)$ & & & & \\
\hline & 2007-2013 & & $0.48(0.34$ to 0.66$)$ & & & & \\
\hline & 2000-2013 & & $0.56(0.46$ to 0.69$)$ & & & & \\
\hline \multirow[t]{3}{*}{ Echemendia $^{23}$} & 2014 & & 1.97 & & & & \\
\hline & 2015 & & 2.41 & & & & \\
\hline & 2016 & & 3.12 & & & & \\
\hline Prien et $a l^{39}$ & $2000-2016$ & 0.01 (0 to 0.01$)$ & $0.44(0.36$ to 0.53$)$ & & $0.13(0.09$ to 0.17$)$ & 1.76 (1.48 to 2.05$)$ & \\
\hline \multicolumn{8}{|l|}{ Tournaments } \\
\hline Fuller et al ${ }^{41}$ & 1998-2004 & & $1.06(0.54$ to 1.58$)$ & & & 2.56 (1.11 to 4.01$)$ & \\
\hline Yoon et $a l^{46}$ & 2000 & & & 1.82 (0.0 to 3.88$)$ & & & \\
\hline Junge et $a l^{151}$ & 1998-2001 & & $1.06(0.02$ to 2.10$)$ & & & & \\
\hline Junge et $a l^{152}$ & 2002 & & 1.89 (0.58 to 3.20$)$ & & & & \\
\hline Hägglund et al ${ }^{43}$ & 2004-2005 & & & 0 & & & 0.55 (0.00 to 1.63$)$ \\
\hline \multirow[t]{2}{*}{ Dvořák et al ${ }^{153}$} & 2002 & & $1.89(0.04$ to 3.74$)$ & & & & \\
\hline & 2006 & & 0.47 (0.00 to 1.39$)$ & & & & \\
\hline $\begin{array}{l}\text { Junge } \\
\text { and Dvořák }\end{array}$ & 1999-2006 & & & & & 2.09 (0.91 to 3.27) & \\
\hline Hägglund et $a / \S^{34}$ & 2006-2008 & 0.0 & $1.07(0.28$ to 1.86$)$ & 0.32 (0.08 to 0.56$)$ & & & \\
\hline Dvořák et al ${ }^{155}$ & 2010 & 0.01 (0 to 0.02 ) & 0.49 (0.00 to 1.45$)$ & & & & \\
\hline Akodu et $a l^{45}$ & 2011 & & $3.24(0.00$ to 9.59$)$ & & & & \\
\hline $\begin{array}{l}\text { Junge and } \\
\text { Dvořák }^{40}\end{array}$ & 1998-2012 & & $1.30(0.93$ to 1.67$)$ & & & 2.10 (1.38 to 2.82$)$ & \\
\hline $\begin{array}{l}\text { Junge and } \\
\text { Dvořák }^{42}\end{array}$ & 2014 & & $0.77(0.33$ to 1.21$)$ & & & & \\
\hline
\end{tabular}

Absence of Cls indicates that either Cls were not reported or that the data necessary to determine Cls were not reported.

*Data from teams based in Northern Europe.

tData from teams based in Southern Europe.

‡Data rounded to maintain consistent format and alignment with the rest of the table. Actual data: $0.004(95 \% \mathrm{Cl} 0.001$ to 0.014$)$.

$\S$ Data for men (nine tournaments) and women (three tournaments) not reported separately. Results are combined rates. ${ }^{155}$

n.s., years studied were not stated. 
the injury was the head, followed by elbow, foot, leg, hip, knee, shoulder, arm and fist. The head (96\%) was the most frequent first point of contact for the injured player. Taken together, head-to-head contact was the most frequent cause of concussions in MLS.

Preliminary review of the video analyses of SRC in MLS players found that visible signs of concussion, observable signs or both (loss of consciousness, clutching or grabbing the head, falling to the ground, being slow to get up or appearing dazed or confused) were found in $28 \%$ of match concussions. This suggests that the use of video review as part of raising awareness and increasing early detection of SRC shows promise, a finding supported by others. ${ }^{24-27}$

Most studies on (head) injuries during domestic seasons were performed on European teams ${ }^{28-36}$; however, there are also data from $\operatorname{Iran}^{37}$ and Qatar. ${ }^{38}$ Nilsson et $a l^{36}$ analysed 136 head and neck injuries (2.2\% of all injuries) in 26 European professional soccer teams between 2001 and 2010. Most head injuries were diagnosed as concussion $(n=48 ; 35.3 \%)$. The mean time loss for concussion was 10.5 days, but $27 \%$ of the concussed players returned to play within 5 days. ${ }^{36}$ While they were able to identify a single significant player-related risk factor for head and neck injuries (being a defender), they were unable to identify any player-related or match-related risk factors for concussions. ${ }^{36}$

In their recent systematic review on epidemiology of head injuries focusing on concussions in team contact sports, Prien et $a l^{39}$ reported on 28 studies conducted in soccer the majority of which $(n=22,78 \%)$ were non-US-based teams. Of the 22 reports, 9 studies reported data from major tournaments and 13 were conducted over the course of the domestic season. Representative data based on professional domestic leagues as well as international tournaments are presented in table 3 . Note that the rates for tables 1 and 2 are per 1000 AEs while the data for professionals are per 1000 player-hours.

\section{Tournaments}

Junge and Dvořák summarised the injury data collected during 51 FIFA-sponsored tournaments and 4 Olympic Games from 1998 to $2012 .^{40}$ In total, 3944 injuries were reported by the team physicians, of which $577(15 \%)$ affected the head or neck. Eighty-one injuries ( $2 \%$ of all injuries) were diagnosed as concussion. Female players incurred significantly more concussions than their male counterparts. Further data on head injuries during international tournaments are available from FIFA tournaments, ${ }^{4142}$ European Championships, ${ }^{34} 4344$ a West African Football Union Nation's Cup $^{45}$ and two Asian tournaments. ${ }^{46}$

Perhaps the most comprehensive examination of head injury mechanisms was prospective analysis of head and neck injuries by Fuller et al during 6 years of international soccer competition. ${ }^{41}$ They concluded that injuries occurred in the middle half of the field when two players approached each other from the side or front and jumped to challenge for a flighted (free) ball. The most likely source of injury in males was the use of the upper extremity (elbow-to-head) and in females it was a head-to-head collision. These data helped convince the International Football Association Board (IFAB) to authorise the referee to red card a player for the use of an intentional elbow to the head.

\section{MANAGEMENT OF HEAD INJURY}

Recognise and remove, assessment, treatment and recovery

The recognition, assessment and treatment of SRC in soccer is important, and for the purposes of the HIS, the findings from the fifth International CISG Consensus Statement are supported and the reader is referred to the consensus statement ${ }^{1}$ as well as the accompanying systematic reviews for a full discussion of these issues. The focus of this section is to review areas that might present unique sport-specific applications or considerations for soccer.

\section{Recognise and remove}

A central feature of any successful concussion management programme is accurate and timely identification of possible injury. Recognition of the injury falls to all of the stakeholders including referees, coaches, administrators, athletes, sports medicine physicians, athletic trainers, physical therapists, neuropsychologists and strength and conditioning specialists. Thus, education of these groups is vital to injury identification.

Referees are trained to work under the 'recognise and refer' principle, which involves recognising the signs and symptoms of possible concussion, stopping the game immediately when there is suspicion of an injury and referral to appropriately trained healthcare professionals. ${ }^{3}$ Player safety, not diagnosis of the injury, is the primary responsibility for officials. Any accommodations for on-field assessments need to take into account current best practices for injury identification and evaluation, and those accommodations must be communicated to those who educate and train officials and coaches.

Educational resources have been published by many organisations, including the Center for Disease Control and Prevention, the NCAA, US Soccer and the United Soccer Coaches. ${ }^{47-49}$ Education is collaborative and as members of the greater soccer community we play an active role and take responsibility to provide up-to-date, scientifically informed information to this population. Dissemination of educational content should be strategic and educational content must be clear, logical and easy to understand with a uniform message. Education drives awareness, progress and policy change.

\section{Role of sensors}

Biomechanical sensors in helmeted sports do not show a specific 'concussion threshold' ${ }^{50}$ Researchers generally accept that impact magnitude alone is an insufficient predictor of concussion. In light of this information, head impact indicators have demonstrated very poor positive predictive value (ie, poor clinical utility) for detecting concussions, ${ }^{50}$ a conclusion supported by the systematic reviews from the CISG. ${ }^{12427}$ Given the growing number of head impact sensors entering the commercial marketplace, there is a need to systematically and independently evaluate the measurement validity and reliability of these systems. Although sensors for non-helmeted sports are being developed (eg, mouthguard, earpiece, retainer, other), none has been validated, and their use for assessment in soccer outside of the research setting is not currently warranted.

\section{Role of spotters}

Increasing attention is being paid to the use of in-game spotters who review live game film, live game play or both to identify visible indicators of possible concussion. ${ }^{24-26}$ Research data suggest that the use of spotters can assist in identifying possible injuries that may go unnoticed by medical staff. However, the institution of such programmes is complex and expensive, placing them out of reach of most non-professional or non-elite organisations.

Carefully conducted studies at the professional level in ice hockey have shown that $>50 \%$ of concussions occur without visible signs. ${ }^{51}$ A study of world rugby showed that approximately 
$21 \%$ of match day concussions were associated with visible signs of SRC on video. ${ }^{26}$ There may be differences between sports in terms of the utility of spotter programmes to recognise SRC. The MLS Spotter programme is an example of the use of spotters in professional soccer (online supplementary appendix B, see section 5: MLS Spotter Programme). The 2018 FIFA World Cup in Russia was the first tournament using spotters to assist and communicate possible injuries to the medical teams on the field.

\section{Barriers to injury recognition and identification in soccer}

There are many barriers to identifying head injuries during a soccer game. ${ }^{5253}$ Soccer is a fast moving game with many players spread out across a large playing surface. Medical and coaching staff have multiple responsibilities during a game that may limit their ability to visualise every minute of the game. Additionally, sight lines often may be compromised, and a complete view of the pitch can be difficult. Players are competitive and at times reluctant to report to coaches and medical staff that they are experiencing symptoms because of the fear of being removed from play. In addition, they may not realise that they are experiencing concussive symptoms, and do not report them. Additional challenges to injury identification include delayed symptom onset, style of play with attempts to draw fouls, only two halves and no time-outs with few stoppages of play, substitution rules and inadequate time to evaluate injured athletes.

There have been discussions at numerous levels, including by the CISG, FIFA, national governing bodies and the NCAA about possible rule modifications to allow sufficient time for medical staff to conduct an acute evaluation when an injury is suspected. The Berlin CISG Statement emphasises this point. 'When a concussion is suspected, the athlete should be removed from the sporting environment, and a multimodal assessment should be conducted in standardised fashion (eg, SCAT5). Sporting bodies should allow adequate time to conduct this evaluation'. ${ }^{1}$ However, any proposed changes to the Laws of the Game in soccer must take into account the potential for gamesmanship or undue pressure on the medical staff to return a player to the field. Law change proposals must be submitted to the International Football Association Board prior to implementation at the professional level. Youth or amateur provisions can and have been made by domestic federations (eg, NCAA, US Soccer).

\section{Assessment}

The assessment of concussion in soccer is ideally multimodal with the SCAT5 and Child SCAT5 serving as useful resources for healthcare providers with experience managing SRC. ${ }^{3}$ The SCAT5 incorporates the Glasgow Coma Scale and 'red flag' signs (such as loss of consciousness, seizures, neck pain, neck tenderness, vomiting, severe or increasing headache) or observable signs (eg, lying motionless on the playing surface, balance or gait difficulties, disorientation, confusion, blank or vacant look) that indicate the need for immediate evaluation by a healthcare provider and possible transportation to an emergency facility. The on-field assessment also includes the Maddock's questions and a cervical spine assessment. The healthcare provider, if available, should make decisions regarding further care and disposition. If no healthcare provider is available, an athlete with suspected SRC should not be allowed to return to play until the player has been evaluated by a healthcare provider. The off-field assessment or office assessment of suspected SRC incorporates background information, a symptom checklist, a cognitive and neurological screen, a balance examination, vestibular and ocular evaluation and other assessments.

\section{Treatment}

Once a player has been diagnosed with a concussion (regardless of level of play), that player should not return to play the same day. Players suspected of having a concussion but not diagnosed with a concussion should be monitored for the emergence of symptoms over the subsequent few days. As the management of SRC is not unique to soccer players, it is not discussed in detail and readers are referred to the CISG. The return to academic and sport process includes a stepwise symptom-limited progression of increased physical, cognitive, work or school-related activity. ${ }^{1}$ The MLS Head Injury/Concussion Evaluation and Management Protocol is provided in online supplementary appendix B.

\section{Recovery}

SRC is largely a time-limited injury with clinical recovery occurring in 7-10 days for $90 \%-95 \%$ of professional players, 14 days in $70 \%-75 \%$ of college players and 21 days for $80 \%-85 \%$ of high school players. Research to date on predicting length of recovery is limited. The most predictable variable associated with prolonged recovery is the immediate symptom burden and symptom severity score. ${ }^{54-56}$ Other potential variables include history of prior concussion, younger age, certain postinjury symptoms (eg, fogginess, headache, dizziness), prior history of headache or migraine or both and prior mental health (eg, depression, anxiety) history. ${ }^{5455}{ }^{57}$ It is important to note that physiological recovery may take longer but this process is poorly understood at present. No specific differences in recovery from SRC in soccer players compared with other athletes have been identified.

\section{Case study: the rugby experience}

Rugby is a sport similar to soccer in that it is fast-paced with a similar number of players participating on a large pitch, with ongoing play with limited stoppage time. Rugby is different than soccer in that it is a tackling sport and an interchange sport (ie, temporary player substitutions permitted), while soccer is a replacement sport (ie, temporary substitutions not permitted).

In 2012, World Rugby instituted a rule to allow temporary substitution, a mandatory and maximum of $10 \mathrm{~min}$, for elite players with suspected SRC. A 'Head Injury Assessment' (HIA) was developed that contained a three-point process. ${ }^{25}$

1. Level one (HIA 1) is an immediate postinjury multimodal evaluation that does not diagnose concussion, but uses the following four components to identify suspected concussion: a) criteria that warrant immediate and permanent removal from play (convulsion, tonic posturing, ataxia, suspected or confirmed LOC, clearly dazed, oculomotor signs, disorientation, confusion, any behaviour change or any sign or symptom of concussion when the athlete is evaluated), b) an off-field screen, c) video review, d) clinical opinion.

2. HIA 2 is completed within 3 hours of injury and consists of the SCAT5 and clinical interview.

3. The HIA 3 is completed $36-48$ hours postinjury and consists of SCAT5 symptoms, balance, cognitive assessment (SAC at a minimum or a computerised neurocognitive test).

Utilisation of HIA has improved recognition and management of injury at the elite level of play. The addition of the HIA2 and HIA3 components incorporates serial assessments and decreases the likelihood of missing injuries associated with delayed symptoms. ${ }^{265859}$ The rugby experience at the elite level is a helpful guide for soccer and likely illustrative of the possibilities for elite play. Similar to soccer, the emphasis for community play in rugby has been on 'recognise and remove' principles. Emphasis 


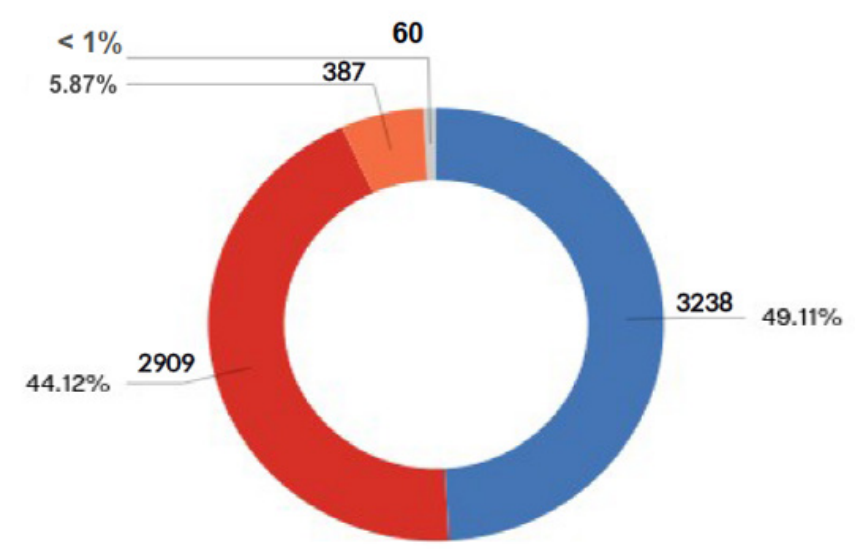

None 1-10 11-20 21-30 $31+$

Figure 1 Percentage of survey respondents with regard to the question as to the number of headers per week by teams in practice in given range categories including none (blue), 1-10 (red), 11-20 (orange), $21+$ combined (grey). This included $0.76 \%$ (21-30 range) and $0.15 \%$ (31+ range).

has also been placed at all levels to remove head-to-head contact with a 'zero tolerance' policy and lower level of tackle, avoiding head contact.

\section{HEADING IN SOCCER: WHAT DO WE KNOW? Biomechanics of heading}

An understanding of heading begins with tracking the flight of the ball, which leads to multiple decisions that experienced players must make very quickly. Youth players often struggle with predicting the flight of the ball and then having to coordinate subsequent body actions and movements necessary to intercept the ball, all of which must happen before any head-ball contact. This entry level skill, tracking the ball, is something coaches can teach with the understanding that the ability to track a ball in flight (and the myriad of accompanying movement responses) takes time to fully develop and coordinate. When considering child development, research would support that heading is a complex motor skill that most children might not learn, much less master, until age 10-12 years. ${ }^{60-64}$ This consideration of developmental trajectories is consistent with guidance issued by US Soccer regarding age-related heading restrictions (see page 11 of online supplementary appendix C). ${ }^{49}$

The skill of heading has been described as consisting of three stages: preparation, contact and follow through ${ }^{65}$ and has been studied in laboratory settings, primarily to measure impact forces associated with heading the ball. The forces measured during the act of heading at the youth level are between 4.5 and $62.9 \mathrm{~g},{ }^{6566}$ approximately $37.9 \mathrm{~g}$ in games at the high school level ${ }^{67}$ and under $43 \mathrm{~g}$ in collegiate soccer studies. ${ }^{68-70}$ While these data are useful in quantifying impact forces, there are concerns related to the sensitivity and specificity of sensor data, ${ }^{70}$ as well as the correlation, if any, to concussive injury. Nonetheless, by most calculations, forces associated with successful purposeful heading seem to be well below most thresholds of head injury. ${ }^{50}$ Applying these measurements during match play is a work in progress.
Frequency of heading

Youth

Data regarding heading in the youth game are limited. What should be a fairly simple task (counting head-ball impacts) can be laborious. Numerous methods have been used such as live or video observers, extrapolating a short segment to the full match and player or coach self-report. Self-report of head-ball impacts has recently been shown to overestimate observer counts by an average of 51\%. ${ }^{71}$ Among youth players aged 13 years and under heading is rare; when it does occur, it is often the result of balls that are thrown in, bounced from the ground or unintentional deflections.

In a group of male and female players aged 9-15 years, it was reported that there was an average of 1.64 headers per game. ${ }^{72}$ A trend for an increase in the number of headers per game as players got older was reported, where the rates for headers per game were 0 for children who are aged 9 years, 0.65 for 10 years, 1.56 for 11 years, 1.11 for 12 years, 2.65 for 13 years and 2.16 for 14 years. $^{72}$ Later studies involving female youth players report heading frequencies ranging from 0.93 headers per game g $^{73}$ to 1.95 headers per game. ${ }^{74}$

A recent retrospective online survey study of youth soccer players (from U-8 to U-15 age groups, boys and girls) asked representatives of 8104 teams from all 55 US Soccer state associations during the fall of 2016 season to determine the occurrence of headers at the youth level. Team representatives who responded to the survey included coaches, team managers and designated adult team contacts (Kontos, 2017, personal communication). This study revealed that approximately 50\% of games at the youth level do not have any headers, approximately $94 \%$ of all games have $1-10$ headers and $<1 \%$ of all games have between 21 and 30 headers (figure 1).

The frequency of self-reported heading during youth practices is similar to those seen during games. Approximately $60 \%$ of practices do not include any headers. In those practices where heading was reported it is likely that the practices incorporated heading-specific skill training (figure 2).

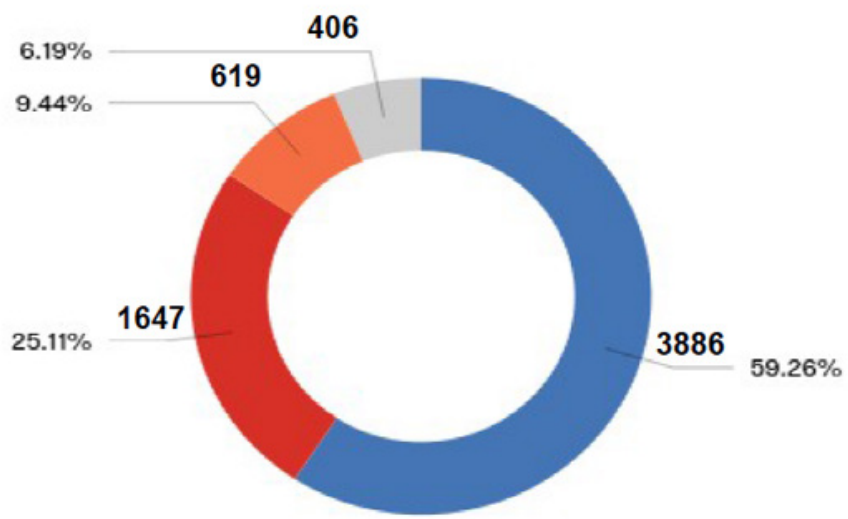

None $1-5 \quad 6-10 \quad 11-15 \quad 16-20 \quad 21+$

Figure 2 Percentage of survey respondents with regard to the question as to the number of headers per week by teams in practice in given range categories including none (blue), 1-5 (red), 6-10 (orange), $11+$ combined (grey). This included $3.35 \%$ (11-15 range), 1.74\% (1620 range) and $1.10 \%$ (21+ range). 
Individual player self-report has also been used to estimate the frequency of heading impacts in youth, collegiate and amateur players. $^{75-77}$ Player self-report has been (very recently) shown to overestimate actual observed counts. ${ }^{71}$ In that small study of 12 youth females over a 20 -game season, the authors concluded 'all players overestimated the number of headers compared with game video. Linear regression analysis indicated that self-reported headers overestimated the actual number of headers counted by $51 \%$ '.

\section{High school and collegiate}

Studies have found a range of heading frequencies and impact forces in youth, high school and collegiate soccer. Frequency of heading in games has been reported to be between $1.0^{78}$ and $2.85^{67}$ in high school and between $1.69^{68}$ and $7.16^{69}$ at the collegiate level. An early prospective study of collegiate soccer players over a season coded heading contacts over nine men's and seven women's games and found that there were 783 headto-ball contacts per minute and 0.753 head-to-ball contacts per minute, respectively. ${ }^{79}$

In addition, this study coded headers as either long punts, crosses and corner kicks, chips and throw ins or direct shots. A total of 689 and 497 headers for males and females respectively were recorded. Heading direct shots was uncommon, accounting for $0.8 \%$ of the men's heading contacts and $1 \%$ of the women's heading contacts; most of these were instances where the player was unable to get their head out of the way of a shot on goal. Long punts accounted for $28 \%$ for the men and $26 \%$ for the women, crosses accounted for $10 \%$ for the men and $13 \%$ for the women, and chips or throw-ins (low velocity short distance passes in the air or ball-to-head contacts after a bounced ball) accounted for $61 \%$ for the men and $60 \%$ for the women. ${ }^{79}$ In this collegiate setting, there was no significant difference between sexes in terms of the frequency of heading or the different types of heading contacts. The majority of heading impacts were chips or throw ins; the direct shot, where a player was not expecting contact and took a blow from a shot, was rare.

\section{Professional}

MLS conducted a video review of all MLS games in 2014 season using 'coders' who examined every head contact (Echemendia, 2017, unpublished data). Those events that involved head-toball contact were coded according to a classification used previously ${ }^{79}$ modified to add whether these occurred during an aerial challenge, defined as any challenge in the air where players collide or otherwise make contact with each other and there is contact between head and ball or head and body. The coding system was found to be highly reliable with inter-rater reliability in excess of $90 \%$. The majority of head-ball impacts were from goal kicks, long punts and chips or throw ins.

A total of 28655 ball-to-head contacts were identified across 297 games in 2014 with an average of 96 head contacts per game. Of the head-to-ball contacts, $30 \%$ were from punts or long kicks, $46 \%$ were coded as chips or throw ins, $16 \%$ arose from crosses or corner kicks, $7 \%$ occurred during an aerial challenge and $2 \%$ were due to a direct shot. The highest percentage of head-toball contacts were from chips and throw-ins. Head contacts that do not include ball contact occurred frequently during aerial challenges. Defenders headed the ball more frequently and most headers occurred in the midfield. Marked variability was found among players and across teams; some players headed the ball frequently while others headed the ball infrequently or not at all. Similarly, some teams tended to use the head less frequently than others. Additional data across several seasons are needed to determine whether these data are consistent over time.

In summary, there appears to be relatively low exposure to heading in youth, interscholastic, collegiate and professional populations; purposeful heading tends to be higher in games than in practice; there are limited data on sex differences in heading and on-field data of heading (and non-header) impacts demonstrate relatively low acceleration values. A threshold for exposures, or risk of long-term cumulative injury, has not been established.

\section{ACUTE AND CHRONIC EFFECTS OF HEADING \\ Neuropsychological}

Conclusive statements regarding whether there are either acute or chronic neurocognitive effects from heading are elusive because studies to date have used different research methodologies, populations, neuropsychological tests, testing paradigms, outcome measures, clinical and psychometric change criteria. Additionally, it is difficult to isolate the individual effects of heading, concussion, the interactions among concussion and heading and concussion and athletic exposure.

Studies have shown no effect of heading on cognitive functions after a $15 \mathrm{~min}$ heading session, ${ }^{80}$ after two practices or games, ${ }^{8182}$ following one season, ${ }^{78798384}$ two seasons ${ }^{85}$ or when assessed as part of a cross-sectional analysis. ${ }^{86}$ Conversely, some older studies have shown minor cumulative effects of heading on cognition. ${ }^{8788}$ A recent systematic review of 22 studies, including 2228 participants, $42 \%$ female, age $13-70$ years found 'no overall effect for heading a football on adverse outcomes'. ${ }^{89}$

Although limited, the preponderance of available data in adolescents and adults does not support the hypothesis that there are intermediate or long-term adverse neurocognitive effects from heading the ball in soccer. Any adverse short-term effects appear to be limited to short-lived transient $(<48$ hours postinjury) changes in postural control, ${ }^{90}$ near point of convergence $^{9192}$ and headache. ${ }^{93}$

\section{Biomarkers}

Maher et $a l^{94}$ reviewed the data related to the biomarkers and neurocognitive outcomes of acute and chronic heading exposure. In terms of short-term effects, Maher et al found increased but reversible changes in brain biomarkers S100-B and NSE (neuron-specific enolase) and no consistent evidence of neurocognitive deficits, the latter likely due to lack of experimental control for player history (eg, number of prior concussions, playing in the leather ball era, learning disabilities, alcohol intake) and the interaction of heading exposure and concussion history. Regarding the long-term effects of heading, Maher et al reported the following: a) no evidence of residual biomarker abnormalities, b) 'the possibility' of lasting deficits in neurocognitive functioning in those with a history of concussion and c) significant differences in neuroimaging or neurophysiological results in five of six studies that compared soccer players and non-playing healthy controls. Regarding the neuroimaging findings, however, Maher et al concluded that the studies were 'limited-particularly in terms of acute concussion where they are lacking completely-and, as such, it is an area of research that should be expanded on in the future to determine whether there truly are adverse effects related to concussions and heading'. ${ }^{94}$

Future research regarding potential effects of heading and soccer participation needs to address host and biopsychosocial variables such as age, sex, other sport and recreational head trauma exposure, personal and family medical and psychiatric 
histories, learning disabilities (including attention deficits), migraine headaches and other health conditions. The measures used to assess cognitive domains should be harmonised along with the timing of neurocognitive testing and the criteria used for assessing meaningful change. Consideration should also be given to using broader (vs screening) measures of cognitive performance (eg, full neuropsychological evaluations, academic performance, standardised test scores).

\section{Neurodegenerative disease and chronic traumatic encephalopathy}

With the increased attention to CTE, there has been developing interest in examining whether a relationship exists between sports participation and the development of CTE pathology or neurodegenerative diseases and, if a relationship does exist, identifying the nature and strength of that relationship.

According to provisional consensus guidelines published in 2016, CTE pathology is characterised by abnormal accumulation of hyperphosphorylated tau protein (P-tau) within neurons, astrocytes and cell processes around small blood vessels in an irregular pattern at the depths of cortical sulci. Interpretation of immunohistochemical stains for P-tau using autopsy tissue is required to make this assessment. P-tau is also a secondary accumulation in many conditions, including Alzheimer's disease, Down syndrome, prion diseases, neurodegeneration with brain iron accumulation type 1, postencephalitic parkinsonism and Niemann-Pick disease type C, among other conditions. P-tau is almost universally detected at autopsy with advanced age. Although there is work in progress, ${ }^{95}$ no accepted criteria for diagnosing CTE in a living person exist at present. Consequently, the incidence of CTE pathology in the general population is unknown.

The data regarding CTE pathology in soccer are limited to a small number of case studies, or retrospective analyses of brain bank specimens. ${ }^{96-103}$ A recent paper by Zuckerman et al has reviewed the data for CTE in contact (soccer, rugby, ice hockey) and collision (American football) sports. ${ }^{104}$ Sulcal depth p-tau consistent with the solitary necessary and sufficient CTE criterion was described in about half of the subjects studied, all of whom had comorbid neurodegenerative diseases (eg, Alzheimer's disease, frontotemporal dementias, amyotrophic lateral sclerosis, etc), which makes it difficult to attribute disease onset and progression solely to CTE pathology. Current research in this area is focusing on the effects of cumulative subconcussive impacts. $^{105}$

It is expected that former soccer players will develop neurodegenerative diseases at the same rates as found in the general population. At present, no data exist that support the hypothesis that soccer participation is a risk factor for the development of neurodegenerative disease. Similarly, at this time, consistent with evidence discussed in the CISG Berlin, ${ }^{1}{ }^{106}$ there are no data to support a causal relationship between soccer and CTE pathology. Continuing research in this area is a necessity to more fully understand whether a link does exist, and if such a link does exist, whether there are approaches for mitigating such risk.

\section{INJURY PREVENTION IN SOCCER}

SRC is an important injury in the sport of soccer at all levels. Identifying interventions that might prevent injury or limit severity remains a challenge. Primary prevention strategies refer to prevention of the injury before it occurs. Risk factors for injury, concussion or both can be categorised as either intrinsic (ie, internal to the athlete such as genetic factors, previous history of concussion or other injury, neuromuscular control, etc) or external (ie, related to the environment such as rules of the game, playing surface, equipment, etc). ${ }^{107}$ For soccer, prevention measures that have been raised include the use of headgear, modification of rules, stricter enforcement of existing rules, restriction of heading, consideration for ball or playing surface characteristics and strength, conditioning and awareness training.

\section{The use of headgear}

Hard shelled sport helmets are designed to prevent catastrophic injury (eg, skull fracture, intracranial hematomas). ${ }^{108}$ They are not currently designed to prevent concussion. In contrast, soft shelled headgear has been developed under the hypothesis of preventing concussion through the use of energy absorbent padding designed to reduce head impact force and subsequent acceleration. Laboratory testing has shown that headgear is effective in reducing impact force at high speeds in simulated head-to-head impacts. ${ }^{109-114}$ Headgear was not found to be effective, however, in reducing acceleration forces during heading. ${ }^{114}$ Testing in the laboratory has also demonstrated that sex differences exist with headgear increasing head impact acceleration in females when compared with males as well as when compared with controls (no headgear). ${ }^{115}$

Other studies have identified that headgear is ineffective at mitigating subtle neurocognitive effects of an acute bout of soccer heading. ${ }^{116}$ In the CISG systematic review on prevention, the conclusion was 'the literature regarding the use of soft shelled protective headgear in sport is mixed'. ${ }^{117}$ The effect of soccer headgear on reducing concussion incidence is unknown as there is a paucity of high-quality field research to date. Soccer headgear can potentially reduce impact acceleration during stiff impacts, such as head-to-head, elbow-to-head, head-to-goalpost or head-to-ground impacts. There is no support for using headgear to decrease the impacts of heading, and in females the addition of headgear may actually increase the forces that the head experiences. ${ }^{115}$ Wearing headgear may also change athlete playing behaviour, giving them a false sense of protection and potentially playing more aggressively (eg, gladiator effect or 'risk compensation'). ${ }^{118} 119$ This is an area where further research is necessary.

\section{Restrictions on heading}

Prevention measures have been instituted in other sports to limit exposure or risk. For example, baseball has moved towards avoiding collisions at home plate, ice hockey has focused on avoiding contact and checking in youth play and football has implemented various measures to limit or avoid contact exposures in youth play. For soccer, although it is clear that heading in and of itself is not associated with significant acute or chronic dysfunction, a common mechanism of SRC being a blow to the head (from another head, elbow, knee or ground) during or after an aerial challenge. This is the basis for the restrictions of heading that were imposed for American youth soccer by US Soccer.

When exploring the issue of limiting heading in specific age groups, it is important to differentiate between restriction (which means to limit) and a ban (which means to prohibit). US Soccer's current policy ${ }^{49}$ on age-related heading prohibits heading for 10 and under (U-11). Youth between the ages of 11 and 12 years (U-12, U-13) may engage in heading training for 'a maximum of $30 \mathrm{~min}$ per week with no more than 15-20 headers per player, per week'. There are no restrictions for U-14 
and older. At present, there are no studies that have empirically examined the effects of age-dependent restrictions on heading.

The US Soccer DA has also implemented additional safety components, which affect approximately 17000 players who participate in the DA. Examples of safety measures that have been incorporated into DA play include small-sided games of 7-9 vs 7-9 (on a smaller field), where there is an emphasis on ball control that minimises long punts and aerial challenges. In addition, these small-sided games promote playing the ball out of the back on the ground (vs a goalkeeper punting the ball), and additional rules that do not allow the goalkeeper to punt the ball or use a drop kick, which may be a consideration in the future. ${ }^{120}$

Other modifications to game play can include modifying the field size, the number of players, whether to use rules such as off-sides, and other rule changes. Additionally, Athletic Trainers (ATC) in the DA are mandated to be available and present for every DA match. Finally, in suspected head injuries, injury substitutions are allowed (that do not count against the team's number of allowed substitutions) and sufficient time is provided for the player to be evaluated by the ATC in real time and determine return to play status. If the player is medically cleared for return to that match, the player replaces the original substitute. ${ }^{49}$

\section{Strength training for the neck}

It seems logical that strengthening the neck muscles should be protective against head injury. The current data are, however, inconsistent. Mihalik et $a l^{121}$ showed no difference in resultant head accelerations across neck strength tertiles in youth hockey players. In American football, increases in neck stiffness, not strength, reduced the odds of moderate or severe impacts. ${ }^{122}$ During heading, Dezman et al ${ }^{123}$ noted that strength imbalances at the neck contributed to greater head acceleration, Bretzin et $a l^{124}$ said that neck strength and girth were negatively correlated to linear and angular acceleration and Caccese et al ${ }^{125}$ found that neck size and strength explained nearly $25 \%$ of the variation in linear and angular acceleration of heading.

Given the observations specific to soccer, improving neck strength should be effective at reducing accelerations during impact. It is well known that the neck musculature is amenable to training ${ }^{126-128}$ and short-term training (5 weeks, twice per week in professional rugby players) can increase neck strength by nearly $20 \%,{ }^{128}$ but simply increasing neck strength and girth of soccer players has no effect on head stabilisation during heading. ${ }^{129}$

The effect of improved neck strength on head stability and reduced injury risk is unknown. The High School Reporting Information Online project collected anthropometric, strength and injury records from over 6000 high school athletes. The data showed that smaller girth (as neck-to-head ratio) and lower neck strength (hand-held dynamometry) were related to increased incidence of concussion. The authors suggested that every one pound increase neck strength was accompanied by a $5 \%$ decrease in the odds of a concussion. ${ }^{130}$ Despite some promising, and conflicting, results, a randomised clinical trial of neck strengthening and subsequent concussive injury remains to be conducted.

\section{Laws of the Game}

The Laws of the Game (Law 12. Fouls and Misconduct) do not single out any specific injury. In the leadup to the 2006 FIFA World Cup, the IFAB was presented with an analysis of head injury mechanisms that prompted them to grant the referee the authority to punish intentional elbows to the head with an immediate red card.

After giving the referee the authority to sanction intentional elbows to the head, a study of Norwegian male professional football players, ${ }^{29}$ reported that strict enforcement and interpretation of the Laws of the Game was indeed associated with a lower incidence of head incidents caused by player-to-player contact and lower incidence of arm-to-head contact. In a 13-year period (before and after the IFAB ruling), all head and facial injuries were reduced in the German professional league. Specifically, concussions have been reduced by $29 \%{ }^{131}$ Both studies indicate that enforcement of existing rules can have an effect on foul play and limit concussive injury.

For the 2014 FIFA World Cup, FIFA's Sports Medical Committee proposed that in cases of suspected concussion, the referee will have the authority to stop the game for $3 \mathrm{~min}$ to allow for an on-field of evaluation of the injured player. The referee will only allow the player to continue with the authorisation of the team doctor. In 2016, US Soccer modified its substitution rule for the Academy programme as follows: 'any player suspected of having head injury may be substituted for evaluation without that substitution counting against the team's total number of allowed substitutions during the game'. ${ }^{49}$

The properties of the ball as well as the playing surface are areas that potentially have implications for injury prevention. There are guidelines for ball size (specified in Law 2) that can affect the forces that the head experiences. It is important that players, parents and coaches use the appropriate sized ball for youth players and attend to the inflation pressure of the ball. ${ }^{132}$ Whether different playing surfaces are associated with different risks for injury is at this time unclear, but is an area of future research. ${ }^{117}$ Finally, an area of significant interest is in awareness training that might increase an athlete's ability to prepare and brace for an impact to the body or head, which might include aerial challenge training for the soccer player. ${ }^{68} 133$ This is an important area of future research.

\section{Educational efforts}

Educational efforts by governing bodies (eg, US Soccer, US Youth Soccer, NCAA, National Federation of High Schools) and government (Centers for Disease Control and Prevention) are important and target athletes, parents, coaches and healthcare providers in terms of the importance of early recognition and management of SRC. ${ }^{134-136}$ US Soccer has produced an educational video on concussions and has implemented this video for coaching and referee certification as well as player and parent education and awareness (www.RecognizeToRecover/Head-andbrain). Finally, the DA has implemented a pledge to concussion awareness by all stakeholders to build a culture of safety around this injury. MLS has also created an internal concussion education video that is shown to all players and coaches in the preseason. Internal MLS data suggest that the video is effective in increasing knowledge on concussion. MLS has also created concussion education posters that are placed in all in team locker rooms.

\section{EXECUTIVE SUMMARY}

The fifth International Consensus Statement on Concussion in Sport provides very useful information, which served as the foundation for leading healthcare professionals with expertise in the sport of soccer to examine the Berlin recommendations from a soccer-specific perspective. In summary, the conclusions made during this summit indicate the following: 
1. Head injuries, specifically concussions, are an important injury for soccer, with lower rates of injuries than many other contact or collision sports for males (compared with American football, ice hockey, rugby and wrestling), but higher rates for females in comparison to other sports. While there is published information on the frequency of SRC at the college, high school and elite levels of play, very few data exist at the youth level of play.

2. The majority of concussions in soccer occur from contact during an aerial challenge, not from purposeful heading of the ball. The most common mechanisms are head-tohead, head-to-body (knee, elbow, foot) or head-to-ground contact.

3. There are limited data regarding the biomechanics of heading forces, but emerging information demonstrates that the forces that occur at all levels appear to be of low magnitude when compared with the forces reported in other sports (eg, American football or ice hockey).

4. Recognition of SRC by all stakeholders (eg, athletes, coaches, referees, healthcare providers) is important. There does not appear to be a role for current sensor technology in injury detection, but there may be a role for 'spotter' programmes that use recognisable signs of concussive injury and can communicate those observations to sideline medical personnel. At the youth and non-elite level, or when no healthcare provider is present, it is important to emphasise the 'recognise and refer' principle of the fifth International Consensus Statement using the CRT5. ${ }^{2}$

5. Consistent with the Berlin consensus statement, there is utility in using a standardised multimodal tool such as the SCAT5 or Child SCAT5 ${ }^{3}{ }^{4}$ when assessing SRC. Athletes with suspected concussion should be removed from play and evaluated by a healthcare provider trained in concussion management. Athletes diagnosed with SRC should not return to play the same day. An initial period (eg, 2448 hours) of both cognitive and physical rest is recommended following concussion. ${ }^{137}$ Graduated return-to-sport and school strategies with progressive increases in cognitive and physical demands following return to baseline levels of functioning represents the ideal approach for return to sport and academics, work activities or both. ${ }^{24}$

6. At this time, for adolescents and adults, the predominance of the available data does not indicate intermediate or longterm adverse neurocognitive effects from heading the ball in soccer. There are no data in youth players. The data that do exist suggest that any adverse effect is likely limited to short term symptoms (eg, headache).

7. There are no prospective data evaluating possible neurodegenerative changes, such as CTE, associated with playing soccer. Data on CTE in soccer players are limited to case reports with comorbid neurodegenerative diseases (eg, Alzheimer's disease, amyotrophic lateral sclerosis). There are no published data that support the view that soccer participation is a risk factor for the development of neurodegenerative disease. Consequently, we are in agreement with the Berlin consensus statement, which states that a causal relationship between playing soccer and CTE has not been established. ${ }^{106}$ We are fully supportive of future research in this area including identifying biomarkers through blood, urine, cerebrospinal fluid and advanced neuroimaging in the assessment and management of SRC.

8. Injury prevention is an important area of further research. Although there has been media attention to the use of headgear in soccer, there are limited studies on effectiveness of such headgear, with the majority of data being laboratory-driven and without on-field application. The laboratory data suggest that headgear may be beneficial in decreasing forces incurred during 'stiff' impacts (eg, head-to-head, head-to-goalpost), but there appears to be less or no benefit when used while heading. ${ }^{113} 114$ This is not surprising since the ball deforms with impact. In addition, whether a decrease in the forces seen in the laboratory results in a decreased incidence of concussion is unclear, as the biomechanical 'threshold' for concussion remains unknown. Importantly, anecdotal reports suggest that the use of headgear may be associated with increased risk compensation, the so-called 'gladiator' effect, where athletes falsely feel protected when using headgear and hence may engage in more aggressive or risky play.

9. Rule enforcement and rule changes have been viewed as essential to injury prevention. In soccer, changes regarding player substitutions, the ' 3 min rule' and enforcement of existing rules (eg, elbow-to-head) all warrant evaluation.

10. It is understood that purposeful heading rarely causes concussion. The current rule changes by US Soccer related to restrictions in heading are supported by modifying game behaviours associated with head injury (decreasing opportunities for the aerial challenge) and taking into account developmental issues regarding neck strength and situational awareness.

11. Athletes, parents, coaches, referees, administrators and healthcare providers can partner to underscore the importance of fair play to keep the sport of soccer safe at all levels.

\section{AREAS OF FUTURE RESEARCH}

There are several areas of future research that include issues not unique to soccer, such as learning more about the difference between clinical and physiological recovery and finding useful biomarkers of injury. Management issues that enhance recovery and prevention efforts that can decrease the incidence or severity of injury are also fruitful topics for future research efforts.

Sport-specific areas of future research include more well-designed evaluations of the mechanism of head injury, specifically SRC, which include proper design and detailed information to be employed at all levels of play in both genders. A better understanding of what occurs during an aerial challenge and the acute and chronic effects, if any, of heading, is needed. In addition, a better understanding of the developmental requirements and visual and motor skill learning needed for proper heading technique. Laboratory-based studies on heading mechanics need to improve ecological validity because studies routinely expose subjects to a far higher frequency of heading than what occurs in a match. We also need to know more about the effect of ball and surface properties, strict enforcement of rules and restricting heading (in an attempt to decrease the number of aerial challenges) on the incidence of concussion and head injury. We need to specifically evaluate whether there are risks for CTE or other neurodegenerative diseases associated with soccer play. Our stakeholders, including athletes, coaches, referees, administrators, referees, along with the healthcare team play a significant role in supporting and enhancing the health and safety of our sport and players. Understanding how we can work together to accomplish this will include continuing to evaluate the issues raised during the Head Injury in Soccer Summit on a regular basis. 
Acknowledgements Head Injury in Soccer Summit Presenters and additional authors are listed alphabetically. Steven Broglio, Rudolph Castellani, George Chiampas, JD, RJE, Chris Giza, Robert Huggins, Thomas Kaminski, Michael Keating, Donald Kirkendall, Anthony Kontos, John Leddy, Jill Loyden, Bert Mandelbaum, Jason Mihalik, Willem Meuwisse, John Parsons, Elizabeth Pieroth, Laura Purcell, Margot Putukian, Kathryn Schneider, Sandra Serafini, Ira Smith, Gary Solomon, Gretchen Thomsen, Ryan Tierney and Michael Turner. All were involved in the development and review of the manuscript. The authors would like to thank the Head Injury in Soccer Summit panelist participants, listed alphabetically: Jim Barlow, Thomas Faro, Dan Garber, Sunil Gulati, Robin Harris, April Kater, Lynn Berling Manuel, Jesse Marsch, Jim Parsons and Taylor Twellman

Collaborators Head Injury Summit Presenters Steven Broglio; Rudolph Castellani; George Chiampas; Jiri Dvorak; Ruben Echemendia; Chris Giza; Robert Huggins; Thomas Kaminski; Michael Keating; Donald Kirkendall; Anthony Kontos; John Leddy; Jill Loyden; Bert Mandelbaum; Jason Mihalik; Willem Meuwisse; John Parsons; Elizabeth Pieroth; Laura Purcell; Margot Putukian; Kathryn Schneider; Sandra Serafini; Ira Smith; Gary Solomon; Gretchen Thomsen; Ryan Tierney; Michael Turner

Contributors This paper summarises a meeting about concussions in soccer. All presenters submitted content relevant to their topic. The seven primary authors worked from the presenter's content to assemble this document. Once fully assembled, all presenters reviewed, edited as needed and approved this submission.

Funding The Head Injury in Soccer: From Science to the Field symposium was held on 21-22 April 2017 in New York City, New York. Support for the symposium was provided by US Soccer, Major League Soccer and the National Women's Soccer League. None of the sponsors had any influence on the content.

Competing interests This paper has 7 primary authors plus 20 other presenters. Gathering disclosures from each will take some time and we did not want to delay this process while we collate all that information. Dr Kahn has expressed an interest in this paper and wanted to start the process. All disclosures are being collated and will be added once replies have been received.

Patient consent Not required.

Provenance and peer review Not commissioned; externally peer reviewed.

ORCID iD

Margot Putukian http://orcid.org/0000-0002-1478-8068

\section{REFERENCES}

1 McCrory P, Meeuwisse W, Dvořák J, et al. Consensus statement on concussion in sport-the 5th international conference on concussion in sport held in Berlin, October 2016. Br J Sports Med 2017;51.

2 Echemendia RJ, Meeuwisse W, McCrory P, et al. The concussion recognition tool. Br J Sports Med 2017:51:870-1.

3 Echemendia RJ, Meeuwisse W, McCrory P, et al. The sport concussion assessment tool 5th edition (SCAT5): background and rationale. Br I Sports Med 2017; 51:848-50.

4 Davis GA, Purcell L, Schneider KJ, et al. The child sport concussion assessment tool 5th edition (Child SCAT5). Br J Sports Med 2017;51:859-61.

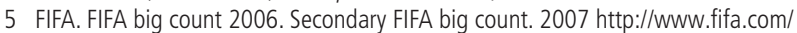
$\mathrm{mm} /$ document/fifafacts/bcoffsurv/bigcount.statspackage $\% 5 f 7024$.pdf

6 USSoccer. US Soccer Development Academy. Secondary US soccer development academy. $2017 \mathrm{http}: / / \mathrm{www}$.ussoccerda.com/overview-what-is-da

7 Faude 0 , Rößler R, Junge A. Football injuries in children and adolescent players: are there clues for prevention? Sports Med 2013;43:819-37.

8 Faude 0 , Rössler R, Junge A, et al. Head injuries in children's football-results from two prospective cohort studies in four European countries. Scand J Med Sci Sports 2017;27:1986-92.

9 Comstock RD, Currie DW, Pierpoint LA, et al. An evidence-based discussion of heading the ball and concussions in high school soccer. JAMA Pediatr 2015;169:830-7.

10 Marar M, Mcllvain NM, Fields SK, et al. Epidemiology of concussions among United States high school athletes in 20 sports. Am J Sports Med 2012;40:747-55.

11 Schallmo MS, Weiner JA, Hsu WK. Sport and sex-specific reporting trends in the epidemiology of concussions sustained by high school athletes. J Bone Joint Surg Am 2017;99:1314-20.

12 Khodaee M, Currie DW, Asif IM, et al. Nine-year study of US high school soccer injuries: data from a national sports injury surveillance programme. Br J Sports Med 2017:51:185-93.

13 Lincoln AE, Caswell SV, Almquist JL, et al. Trends in concussion incidence in high school sports: a prospective 11-year study. Am J Sports Med 2011;39:958-63.

14 Rosenthal JA, Foraker RE, Collins CL, et al. National high school athlete concussion rates From 2005-2006 to 2011-2012. Am J Sports Med 2014;42:1710-5.

15 Boden BP, Kirkendall DT, Garrett WE. Concussion incidence in elite college soccer players. Am J Sports Med 1998;26:238-41.
16 Zuckerman SL, Totten DJ, Rubel KE, et al. Mechanisms of injury as a diagnostic predictor of sport-related concussion severity in football, basketball, and soccer: results from a regional concussion registry. Neurosurgery 2016;63:102-12.

17 O'Kane JW, Levy MR, Neradilek M, et al. Evaluation of the zachery lystedt law among female youth soccer players. Phys Sportsmed 2014;42:39-44.

18 Elbin RJ, Sufrinko A, Schatz P, et al. Removal from play after concussion and recovery time. Pediatrics 2016;138:e20160910.

19 Taubman B, Rosen F, McHugh J, et al. The timing of cognitive and physical rest and recovery in concussion. J Child Neurol 2016;31:1555-60.

20 NCAA. NCAA Injury Surveillance Program. Secondary NCAA Injury Surveillance Program. 2017 http://www.ncaa.org/sport-science-institute/ncaa-injury-surveillanceprogram

21 Roos KG, Wasserman EB, Dalton SL, et al. Epidemiology of 3825 injuries sustained in six seasons of national collegiate athletic association men's and women's soccer (2009/2010-2014/2015). Br J Sports Med 2017:51:1029-34.

22 Zuckerman SL, Kerr ZY, Yengo-Kahn A, et al. Epidemiology of sports-related concussion in NCAA athletes from 2009-2010 to 2013-2014: incidence, recurrence, and mechanisms. Am J Sports Med 2015;43:2654-65.

23 Echemendia RE. Review of MLS policy and discussion of concussion management. Manhattan Beach, CA: Major League Soccer 2017 Medical Symposium, 2017.

24 Echemendia RJ, Broglio SP, Davis GA, et al. What tests and measures should be added to the SCAT3 and related tests to improve their reliability, sensitivity and/or specificity in sideline concussion diagnosis? A systematic review. Br I Sports Med 2017;51:895-901.

25 Fuller CW, Fuller GW, Kemp SP, et al. Evaluation of World Rugby's concussion management process: results from rugby world cup 2015. Br I Sports Med 2017;51:64-9.

26 Fuller GW, Kemp SP, Raftery M. The accuracy and reproducibility of video assessment in the pitch-side management of concussion in elite rugby. I Sci Med Sport 2017;20:246-9.

27 Patricios J, Fuller GW, Ellenbogen R, et al. What are the critical elements of sideline screening that can be used to establish the diagnosis of concussion? A systematic review. Br J Sports Med 2017;51:888-94.

28 Andersen TE, et al. Mechanisms of head injuries in elite football. Br I Sports Med 2004;38:690-6

29 Biørneboe J, Bahr R, Dvorak J, et al. Lower incidence of arm-to-head contact incidents with stricter interpretation of the Laws of the Game in Norwegian male professional football. Br J Sports Med 2013;47:508-14.

30 Dupont G, Nedelec M, McCall A, et al. Effect of 2 soccer matches in a week on physical performance and injury rate. Am I Sports Med 2010;38:1752-8.

31 Ekstrand J, Hägglund M, Fuller CW. Comparison of injuries sustained on artificial turf and grass by male and female elite football players. Scand I Med Sci Sports 2011:21:824-32.

32 Ekstrand J, Hägglund M, Waldén M. Injury incidence and injury patterns in professional football: the UEFA injury study. Br J Sports Med 2011;45:553-8.

33 Gaulrapp H, Hartmut G, Becker A, et al. Injuries in women's soccer: a 1-year all players prospective field study of the women's Bundesliga (German premier league). Clin I Sport Med 2010;20:264-71.

34 Hägglund $M$, Waldén $M$, Ekstrand J. UEFA injury study-an injury audit of European championships 2006 to 2008. Br J Sports Med 2009;43:483-9.

35 Jacobson I, Tegner Y. Injuries among Swedish female elite football players: a prospective population study. Scand I Med Sci Sports 2007;17:84-91.

36 Nilsson $\mathrm{M}$, Hägglund $\mathrm{M}$, Ekstrand J, et al. Head and neck injuries in professional soccer. Clin J Sport Med 2013;23:255-60.

37 Hassabi M, Mohammad-Javad Mortazavi S, Giti MR, et al. Injury profile of a professional soccer team in the premier league of iran. Asian I Sports Med 2010;1:201-8.

38 Eirale C, Tol JL, Whiteley R, et al. Different injury pattern in goalkeepers compared to field players: a three-year epidemiological study of professional football. J Sci Med Sport 2014:17:34-8

39 Prien A, Grafe A, Rössler R, et al. Epidemiology of head injuries focusing on concussions in team contact sports: a systematic review. Sports Med 2018:48:953-69.

40 Junge A, Dvorak J. Injury surveillance in the world football tournaments 1998-2012. Br J Sports Med 2013;47:782-8.

41 Fuller CW, Junge A, Dvorak J. A six year prospective study of the incidence and causes of head and neck injuries in international football. Br I Sports Med 2005;39:i3-9

42 Junge A, Dvořák J. Football injuries during the 2014 FIFA World Cup. Br J Sports Med 2015;49:599-602.

43 Hägglund $\mathrm{M}$, Waldén $\mathrm{M}$, Ekstrand J. Injuries among male and female elite football players. Scand J Med Sci Sports 2009;19:819-27.

44 Waldén $M$, Hägglund $M$, Ekstrand J. Football injuries during European Championships 2004-2005. Knee Surg Sports Traumatol Arthrosc 2007;15:1155-62.

45 Akodu AK, Owoeye OB, Ajenifuja M, et al. Incidence and characteristics of injuries during the 2011 West Africa Football Union (WAFU) Nations' Cup. Afr J Med Med Sci 2012;41:423-8. 
46 Yoon YS, Chai M, Shin DW. Football injuries at Asian tournaments. Am J Sports Med 2004:32:36-42.

47 NCAA. Concussion educational resources. secondary concussion educational resources. 2017 www.ncaa.org/sport-science-institute/concussion-educationalresources

48 United Soccer Coaches. Get aHEAD safely in soccer online diploma course. secondary Get aHEAD safely in Soccer Online Diploma Course. 2017 https:// unitedsoccercoaches.org/heading

49 U.S USSoccer. Soccer recognize 2 recover concussion guidelines secondary U.S. 2017 https://www.ussoccer.com/stories/2015/12/02/20/59/151202-us-soccer-announcesrecognize-to-recover-player-health-and-safety-program

50 Mihalik JP, Lynall RC, Wasserman EB, et al. Evaluating the "threshold theory": can head impact indicators help? Med Sci Sports Exerc 2017;49:247-53.

51 Echemendia RJ, Bruce JM, Meeuwisse W, et al. Can visible signs predict concussion diagnosis in the National Hockey League? Br J Sports Med 2018;52:1149-54.

52 Chrisman SP, Quitiquit C, Rivara FP. Qualitative study of barriers to concussive symptom reporting in high school athletics. J Adolesc Health 2013;52:330-5.

53 Rivara FP, Schiff MA, Chrisman SP, et al. The effect of coach education on reporting of concussions among high school athletes after passage of a concussion law. Am J Sports Med 2014;42:1197-203.

54 Iverson GL, Gardner AJ, Terry DP, et al. Predictors of clinical recovery from concussion: a systematic review. Br J Sports Med 2017;51:941-8.

55 Morgan CD, Zuckerman SL, Lee YM, et al. Predictors of postconcussion syndrome after sports-related concussion in young athletes: a matched case-control study. $J$ Neurosurg Pediatr 2015;15:589-98.

56 Putukian M, Echemendia R, Dettwiler-Danspeckgruber A, et al. Prospective clinical assessment using Sideline Concussion Assessment Tool-2 testing in the evaluation of sport-related concussion in college athletes. Clin J Sport Med 2015:25:36-42

57 Zemek R, Barrowman N, Freedman SB, et al. Clinical risk score for persistent postconcussion symptoms among children with acute concussion in the ED. JAMA 2016;315:1014-25

58 Tucker R, Raftery M, Fuller GW, et al. A video analysis of head injuries satisfying the criteria for a head injury assessment in professional Rugby Union: a prospective cohort study. Br J Sports Med 2017;51:1147-51.

59 Tucker R, Raftery M, Kemp S, et al. Risk factors for head injury events in professional rugby union: a video analysis of 464 head injury events to inform proposed injury prevention strategies. Br J Sports Med 2017;51:1152-7.

60 Baxter-Johes ADG, Malina RM. et a/Growth and maturation issues in elite hyoung athletes: normal variation and training. In: Maffulli N, Chan KM, MacDonald R, Malina RM, Parker T, . Sports medicine for specific ages and abilities. London: Harcourt Publishers Limited, 2001:95-108.

61 Greydanus DE, Pratt HD. Adolescent growth and development and sport participation. In: Patel DR, Greydanus DE, Baker RJ, eds. Pediatric practise: sports medicine. New York: McGraw-Hill Companies, Inc., 2009:15-25.

62 Haywood KM, Getchell N. Life span motor development. 6th ed. Human Kinetics: Champaign, IL, 2014.

63 Lefebvre C, Reid G. Prediction in ball catching by children with and without a developmental coordination disorder. Adapted Physical Activity Quarterly 1998;15:299-315.

64 Purcell L. Sport Spot: Sport readiness in children and youth. Paediatr Child H/th 2005; 16:343-5.

65 Hanlon E. Biomechanics of heading in youth soccer [Dissertation: Wayne State University, 2009.

66 Chrisman SPD, Ebel BE, Stein E, et al. Head impact exposure in youth soccer and variation by age and sex. Clin J Sport Med 2017.

67 McCuen E, Svaldi D, Breedlove K, et al. Collegiate women's soccer players suffer greater cumulative head impacts than their high school counterparts. J Biomech 2015:48:3720-3.

68 Lamond LC, Caccese JB, Buckley TA, et al. Linear acceleration in direct head contact across impact type, player position, and playing scenario in collegiate women's soccer players. J Athl Train 2018;53:115-21.

69 Lynall RC, Clark MD, Grand EE, et al. Head impact biomechanics in women's college soccer. Med Sci Sports Exerc 2016;48:1772-8.

70 Press JN, Rowson S. Quantifying head impact exposure in collegiate women's soccer. Clin J Sport Med 2017;27:104-10.

71 Harriss A, Walton DM, Dickey JP. Direct player observation is needed to accurately quantify heading frequency in youth soccer. Res Sports Med 2018;26:191-8.

72 Salinas CM, Webbe FM, Devore TT. The epidemiology of soccer heading in competitive youth players. J Clin Sport Psychol 2009;3:15-33.

73 Chrisman SP, Mac Donald CL, Friedman S, et al. Head impact exposure during a weekend youth soccer tournament. J Child Neurol 2016;31:971-8.

74 Hanlon EM, Bir CA. Real-time head acceleration measurement in girls' youth soccer. Med Sci Sports Exerc 2012;44:1102-8.

75 Catenaccio E, Caccese J, Wakschlag N, et al. Validation and calibration of headcount, a self-report measure for quantifying heading exposure in soccer players. Res Sports Med 2016;24:416-25.
76 Lipton ML, Ifrah C, Stewart WF, et al. Validation of HeadCount-2w for estimation of two-week heading: comparison to daily reporting in adult amateur player. I Sci Med Sport 2018;21:363-7

77 Stewart WF, Kim N, Ifrah CS, et al. Symptoms from repeated intentional and unintentional head impact in soccer players. Neurology 2017;88:901-8.

78 Kaminski TW, Cousino ES, Glutting JJ. Examining the relationship between purposefu heading in soccer and computerized neuropsychological test performance. Res $Q$ Exerc Sport 2008;79:235-44.

79 Putukian M, Echemendia RJ, Evans TA, et al. Effects of heading contacts in collegiate soccer plaeyrs on cognitive dunction: Prospective neurophusiological assessment over a season. Clin J Sports Med 2001;11:288-96.

80 Rieder C, Jansen P. No neuropsychological consequence in male and female soccer players after a short heading training. Arch Clin Neuropsychol 2011;26:583-91.

81 Kontos AP, Dolese A, Elbin RJ, et al. Relationship of soccer heading to computerized neurocognitive performance and symptoms among female and male youth soccer players. Brain Inj 2011;25:1234-41

82 Putukian M, Echemendia RJ, Mackin S. The acute neuropsychological effects of heading in soccer: a pilot study. Clin J Sport Med 2000;10:104-9.

83 Forbes CR, Glutting JJ, Kaminski TW. Examining neurocognitive function in previously concussed interscholastic female soccer players. Appl Neuropsychol Child 2016;5:1-11.

84 Janda DH, Bir CA, Cheney AL. An evaluation of the cumulative concussive effect of soccer heading in the youth population. Inj Control Saf Promot 2002;9:25-31.

85 Stephens R, Rutherford A, Potter D, et al. Neuropsychological consequence of socce play in adolescent U.K. School team soccer players. J Neuropsychiatry Clin Neurosci 2010:22:295-303.

86 Guskiewicz KM, Marshall SW, Broglio SP, et al. No evidence of impaired neurocognitive performance in collegiate soccer players. Am J Sports Med 2002;30:157-62

87 Webbe FM, Ochs SR. Recency and frequency of soccer heading interact to decrease neurocognitive performance. App/ Neuropsychol 2003;10:31-41.

88 Witol AD, Webbe FM. Soccer heading frequency predicts neuropsychological deficits. Arch Clin Neuropsychol 2003;18:397-417.

89 Kontos AP, Braithwaite R, Chrisman SPD, et al. Systematic review and meta-analysis of the effects of football heading. Br J Sports Med 2017;51:1118-24.

90 Haran FJ, Tierney R, Wright WG, et al. Acute changes in postural control after soccer heading. Int J Sports Med 2013;34:350-4.

91 Hwang S, Ma L, Kawata K, et al. Vestibular dysfunction after subconcussive head impact. J Neurotrauma 2017:34:8-15.

92 Kawata K, Tierney R, Phillips J, et al. Effect of repetitive sub-concussive head impacts on ocular near point of convergence. Int J Sports Med 2016;37:405-10.

93 Schmitt DM, Hertel J, Evans TA, et al. Effect of an acute bout of soccer heading on postural control and self-reported concussion symptoms. Int I Sports Med 2004:25:326-31

94 Maher ME, Hutchison M, Cusimano M, et al. Concussions and heading in soccer: a review of the evidence of incidence, mechanisms, biomarkers and neurocognitive outcomes. Brain Inj 2014;28:271-85.

95 Montenigro PH, Baugh CM, Daneshvar DH, et al. Clinical subtypes of chronic traumatic encephalopathy: literature review and proposed research diagnostic criteria for traumatic encephalopathy syndrome. Alzheimers Res Ther 2014;6:68.

96 Bieniek KF, Ross OA, Cormier KA, et al. Chronic traumatic encephalopathy pathology in a neurodegenerative disorders brain bank. Acta Neuropathol 2015:130:877-89.

97 Geddes JF, Vowles GH, Nicoll JA, et al. Neuronal cytoskeletal changes are an early consequence of repetitive head injury. Acta Neuropathol 1999:98:171-8.

98 Grinberg LT, Anghinah R, Nascimento CF, et al. Chronic traumatic encephalopathy presenting as alzheimer's disease in a retired soccer player. J Alzheimers Dis 2016;54:169-74.

99 Hales C, Neill S, Gearing M, et al. Late-stage CTE pathology in a retired soccer player with dementia. Neurology 2014;83:2307-9.

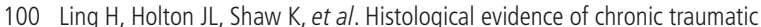
encephalopathy in a large series of neurodegenerative diseases. Acta Neuropathol 2015;130:891-3.

101 Ling H, Morris HR, Neal JW, et al. Mixed pathologies including chronic traumatic encephalopathy account for dementia in retired association football (soccer) players. Acta Neuropathol 2017:133:337-52.

102 McKee AC, Cantu RC, Nowinski CJ, et al. Chronic traumatic encephalopathy in athletes: progressive tauopathy after repetitive head injury. J Neuropathol Exp Neurol 2009;68:709-35.

103 McKee AC, Daneshvar DH, Alvarez VE, et al. The neuropathology of sport. Acta Neuropathol 2014;127:29-51.

104 Zuckerman SL, Brett BL, Jeckell A, et al. Chronic traumatic encephalopathy and neurodegeneration in contact sports and american football. J Alzheimers Dis 2018:66:37-55

105 Huber BR, Alosco ML, Stein TD, et al. Potential long-term consequences of concussive and subconcussive injury. Phys Med Rehabil Clin N Am 2016;27:503-11.

106 Manley G, Gardner AJ, Schneider KJ, et al. A systematic review of potential long-term effects of sport-related concussion. Br J Sports Med 2017;51:969-77. 
107 Meeuwisse WH, Tyreman H, Hagel B, et al. A dynamic model of etiology in sport injury: the recursive nature of risk and causation. Clin J Sport Med 2007;17:215-9.

108 Schneider DK, Grandhi RK, Bansal P, et al. Current state of concussion prevention strategies: a systematic review and meta-analysis of prospective, controlled studies. Br J Sports Med 2017;51:1473-82.

109 Broglio SP, Ju YY, Broglio MD, et al. The efficacy of soccer headgear. J Athl Train 2003;38:220-4.

110 Hrysomallis C. Impact energy attentuation of protective football headgear against a yielding surface. J Sci Med Sport 2004;7:156-64.

111 McIntosh A, McCrory P, Finch CF. Performance enhanced headgear: a scientific approach to the development of protective headgear. $\mathrm{Br} /$ Sports Med 2004:38:46-9.

112 McIntosh AS, McCrory P. Impact energy attenuation performance of football headgear. Br J Sports Med 2000;34:337-41.

113 Naunheim RS, Ryden A, Standeven J, et al. Does soccer headgear attenuate the impact when heading a soccer ball? Acad Emerg Med 2003;10:85-90.

114 Withnall C, Shewchenko N, Wonnacott M, et al. Effectiveness of headgear in football. Br J Sports Med 2005;39:i40-8.

115 Tierney RT, Higgins M, Caswell SV, et al. Sex differences in head acceleration during heading while wearing soccer headgear. J Ath/ Train 2008;43:578-84.

116 Elbin RJ, Beatty A, Covassin T, et al. A preliminary examination of neurocognitive performance and symptoms following a bout of soccer heading in athletes wearing protective soccer headbands. Res Sports Med 2015;23:203-14.

117 Emery CA, Black AM, Kolstad A, et al. What strategies can be used to effectively reduce the risk of concussion in sport? A systematic review. Br J Sports Med 2017:51:978-84.

118 Daneshvar DH, Baugh CM, Nowinski CJ, et al. Helmets and mouth guards: the role of personal equipment in preventing sport-related concussions. Clin Sports Med 2011;30:145-63.

119 Hagel B, Meeuwisse W. Risk compensation: a "side effect" of sport injury prevention? Clin J Sport Med 2004;14:193-6.

120 Caccese JB, Lamond LC, Buckley TA, et al. Reducing purposeful headers from goal kicks and punts may reduce cumulative exposure to head acceleration. Res Sports Med 2016;24:407-15.

121 Mihalik JP, Guskiewicz KM, Marshall SW, et al. Does cervical muscle strength in youth ice hockey players affect head impact biomechanics? Clin J Sport Med 2011:21:416-21.

122 Schmidt JD, Guskiewicz KM, Blackburn JT, et al. The influence of cervical muscle characteristics on head impact biomechanics in football. Am J Sports Med 2014;42:2056-66.

123 Dezman ZD, Ledet EH, Kerr HA. Neck strength imbalance correlates with increased head acceleration in soccer heading. Sports Health 2013;5:320-6.

124 Bretzin AC, Mansell JL, Tierney RT, et al. Sex differences in anthropometrics and heading kinematics among division i soccer athletes. Sports Health 2017;9:168-73.

125 Caccese JB, Buckley TA, Tierney RT, et al. Head and neck size and neck strength predict linear and rotational acceleration during purposeful soccer heading. Sports Biomech 2018;17:462-76.

126 Conley MS, Stone MH, Nimmons M, et al. Specificity of resistance training responses in neck muscle size and strength. Eur J Appl Physiol Occup Physiol 1997;75:443-8.

127 Conley MS, Stone MH, Nimmons M, et al. Resistance training and human cervical muscle recruitment plasticity. J App/ Physiol 1997;83:2105-11.

128 Geary K, Green BS, Delahunt E. Effects of neck strength training on isometric neck strength in rugby union players. Clin J Sport Med 2014;24:502-8.

129 Mansell J, Tierney RT, Sitler MR, et al. Resistance training and head-neck segment dynamic stabilization in male and female collegiate soccer players. J Ath/ Train 2005;40:310-9.

130 Collins CL, Fletcher EN, Fields SK, et al. Neck strength: a protective factor reducing risk for concussion in high school sports. J Prim Prev 2014;35:309-19.

131 Beaudouin F, Aus der Fünten K, Tröß T, et al. Match situations leading to head injuries in professional male football (soccer)-a video-based analysis over 12 years. Clin J Sport Med 2018:1.
132 Bible F. Soccer ball sizes. secondary soccer ball sizes. 2014 https://www.footballbible.com/soccer-info/soccer-ball-sizes.html

133 Caccese JB, Kaminski TW. Minimizing head acceleration in soccer: a review of the literature. Sports Med 2016:46:1591-604.

134 Kroshus E, Babkes Stellino M, Chrisman SPD, et al. Threat, pressure, and communication about concussion safety: implications for parent concussion education. Health Educ Behav 2018;45:254-61.

135 Kroshus E, Baugh CM. Concussion education in U.S. Collegiate Sport: what is happening and what do athletes want? Health Educ Behav 2016;43:182-90.

136 Kroshus E, Rivara FP, Whitlock KB, et al. Disparities in athletic trainer staffing in secondary school sport: implications for concussion identification. Clin J Sport Med 2017;27:542-7.

137 Schneider KJ, Leddy JJ, Guskiewicz KM, et al. Rest and treatment/rehabilitation following sport-related concussion: a systematic review. Br J Sports Med 2017:51:930-4.

138 Powell JW, Barber-Foss KD. Traumatic brain injury in high school athletes. JAMA 1999:282:958-63.

139 Schulz MR, Marshall SW, Mueller FO, et al. Traumatic brain injury in high school athletes. Am J Epidemio/ 2004;160:937.

140 Gessel LM, Fields SK, Collins CL, et al. Concussions among United States high schoo and collegiate athletes. J Athl Train 2007;42:495-503.

141 O'Connor KL, Baker MM, Dalton SL, et al. Epidemiology of sport-related concussions in high school athletes: national athletic treatment, injury and outcomes network (NATION), 2011-2012 Through 2013-2014. J Ath/ Train 2017;52:175-85.

142 Covassin T, Swanik CB, Sachs ML. Sex Differences and the incidence of concussions among collegiate athletes. J Ath/ Train 2003;38:238-44.

143 Agel J, Evans TA, Dick R, et al. Descriptive epidemiology of collegiate men's soccer injuries: national collegiate athletic association injury surveillance system, 19881989 through 2002-2003. J Ath/ Train 2007;42:270-7.

144 Dick R, Putukian M, Agel J, et al. Descriptive epidemiology of collegiate women's soccer injuries: national collegiate athletic association injury surveillance system 1988-1989 through 2002-2003. J Athl Train 2007;42:278-85.

145 Chandran A, Barron MJ, Westerman BJ, et al. Multifactorial examination of sexdifferences in head injuries and concussions among collegiate soccer players: NCAA ISS, 2004-2009. Inj Epidemiol 2017;4:28

146 Fuller CW, Dick RW, Corlette J, et al. Comparison of the incidence, nature and cause of injuries sustained on grass and new generation artificial turf by male and female football players. Part 2: training injuries. Br J Sports Med 2007:41 Suppl 1:i27-i32.

147 Fuller CW, Dick RW, Corlette J, et al. Comparison of the incidence, nature and cause of injuries sustained on grass and new generation artificial turf by male and female football players. Part 1: match injuries. Br J Sports Med 2007;41 Suppl 1:i20-i26.

148 Kerr ZY, Roos KG, Djoko A, et al. Epidemiologic measures for quantifying the incidence of concussion in national collegiate athletic association sports. J Ath/ Train 2017; 52:167-74

149 Waldén M, Hägglund M, Ekstrand J. Injuries in Swedish elite football-a prospective study on injury definitions, risk for injury and injury pattern during 2001. Scand J Med Sci Sports 2005;15:118-25.

150 Waldén M, Hägglund M, Orchard J, et al. Regional differences in injury incidence in European professional football. Scand J Med Sci Sports 2013:23:424-30.

151 Junge A, Dvorak J, Graf-Baumann T. Football Injuries during the world cup 2002. Am J Sports Med 2004;32:23-7.

152 Junge A, Dvorak J, Graf-Baumann T, et al. Football injuries during FIFA tournaments and the Olympic Games, 1998-2001: development and implementation of an injuryreporting system. Am J Sports Med 2004:32:80S-9.

153 Dvorak J, Junge A, Grimm K, et al. Medical report from the 2006 FIFA world cup Germany. Br J Sports Med 2007;41:578-81.

154 Junge A, Dvorak J. Injuries in female football players in top-level international tournaments. Br J Sports Med 2007:41 Suppl 1:i3-i7.

155 Dvorak J, Junge A, Derman W, et al. Injuries and illnesses of football players during the 2010 FIFA world cup. Br J Sports Med 2011;45:626-30. 